\title{
À la recherche de l'authenticité perdue
}

In search of lost authenticity

\section{Henri Lecomte}

\section{(2) OpenEdition}

Journals

Édition électronique

URL : http://journals.openedition.org/ethnomusicologie/1131

ISSN : 2235-7688

Éditeur

ADEM - Ateliers d'ethnomusicologie

Édition imprimée

Date de publication : 1 décembre 1996

Pagination : 115-129

ISBN : 978-2-8257-0559-9

ISSN : $1662-372 X$

Référence électronique

Henri Lecomte, «À la recherche de l'authenticité perdue », Cahiers d'ethnomusicologie [En ligne],

9| 1996, mis en ligne le 05 janvier 2012, consulté le 30 avril 2019. URL : http://

journals.openedition.org/ethnomusicologie/1131

Ce document a été généré automatiquement le 30 avril 2019.

Tous droits réservés 


\title{
À la recherche de l'authenticité perdue
}

\author{
In search of lost authenticity
}

\section{Henri Lecomte}

Quiconque a des activités directement liées aux musiques traditionnelles, et travaille parfois dans des "contrées exotiques ", se voit souvent considéré par le profane comme une sorte de moderne Indiana Jones, à la recherche d'une mythique "authenticité perdue ». Il s'y ajoute tout un ensemble de connotations écologiques ou humanitaires qui se rattachent à la sauvegarde de cultures en danger. Ce danger me semble d'ailleurs souvent exagéré en ce qui concerne les musiques, même si les agressions du monde industriel à l'égard des sociétés autochtones et la précarité des conditions de vie de ces dernières sont une triste réalité.

Le problème de l'authenticité se pose effectivement à tous les niveaux du travail sur ces musiques "traditionnelles", notamment à celui de leur présentation à un public occidental, que ce soit par des concerts, l'édition de disques compacts, de livres ou d'articles dans la presse, spécialisée ou non. On ne peut que s'interroger sur l'adéquation qui peut exister entre la présentation que l'on offre au public occidental d'une culture musicale ou de l'un de ses aspects et cette culture elle-même.

Une chose est certaine, la neutralité n'est pas possible, même à l'intérieur de notre propre culture. On a des exemples dans le domaine français de joueurs de fifre ou de vielle, qui sont parallèlement joueurs de clairon ou de tuba dans la fanfare municipale et chantres ou joueurs d'harmonium à l'église (Mabru 1988). Présentera-t-on un aspect déformé des pratiques de ces musiciens routiniers en n'offrant au public que les pièces de vielle ou de fifre aux dépens de la fanfare et du plain-chant? La recherche de l'objectivité est aussi illusoire que celle de l'authenticité. Il faudrait peut-être, comme l'a fait notamment Michel Leiris dans le domaine de l'ethnologie, parler autant de soi que de la musique que l'on étudie, pour expliquer ses propres choix. J'épargnerai cette approche au lecteur, mais c'est cependant à partir d'expériences personnelles en Asie centrale et en Sibérie, ainsi que de la pratique d'un instrument étranger à ma culture d'origine, le shakuhachi, que je tenterai de poser certains problèmes liés à cette notion d'authenticité. 
4 N'entendons pas ici authenticité dans un sens philosophique, heideggerien ou sartrien, mais dans un sens anthropologique, lié à l'adéquation d'une expression musicale avec la culture dont est issu le musicien. La question se pose d'ailleurs bien souvent plus pour l'observateur extérieur que pour le musicien lui-même. Si on demande à un musicien kirghiz ce qu'il fait dans la vie, il y a de fortes chances qu'il vous réponde : «Je fais de la musique », sans juger utile de préciser qu'il pratique la musique kirghize, alors pourtant que les années de présence russe ont répandu la musique occidentale dans toute la république. Le problème d'identité culturelle ne semble pas se poser (tout au moins à ce niveau : nous verrons que l'utilisation de l'épopée de Manas à des fins identitaires prouve que le problème existe), même si, dans les écoles, on met l'accent sur l'enseignement des instruments nationaux, principalement la guimbarde temir ooz komuz et le luth komuz ${ }^{1}$

5 Le problème de l'évolution des musiques se pose également. Restons au Kirghizstan où, selon l'usage hérité des ethnomusicologues soviétiques, on ne peut pas toujours éviter la formule peu gratifiante selon laquelle les autorités culturelles ont rassemblé, dans la bibliothèque ou la maison de la culture du chef-lieu de l'oblast, celles et ceux qui leur paraissent être les meilleurs musiciens de la région. On peut y entendre un éventail important d'approches de la musique ressenties comme identitaires, allant du grand ensemble d'instruments traditionnels «améliorés " jouant une musique harmonisée, au virtuose local de komuz, en passant par un chanteur d'épopée ou de chants patriotiques de la seconde guerre mondiale. Les organisateurs ont compris que nous recherchions des musiques « authentiques », et en conséquence nous n'entendrons ni accordéon ni guitare. Tout le reste, pour eux, participera d'une même entité, la musique kirghize. Les choix esthétiques du collecteur et des responsables culturels locaux, généralement très attachés à leur culture, ne seront pas nécessairement les mêmes. Une dame kirghize travaillant à la radio, sera outrée du choix que nous avons fait de représenter sur un disque compact (Lecomte, 1995) l'épopée de Manas, fierté du Kirghizstan, par un vieux chanteur de village, Kaba Atabekov, des plus traditionnels puisqu'il nous a déclaré «avoir appris en rêvant l'épopée que Manas lui a enseigné en personne». Pourquoi n'avais-je pas enregistré untel, artiste officiel et " la plus grande voix de Bichkek », la capitale ? Je n'ai pu que répondre qu'il s'agissait d'un goût personnel pour les formes rurales anciennes ${ }^{2}$.

\section{Authenticité et politique}

Cette revendication d'ancienneté existe pourtant en Kirghizie, où elle est liée à une volonté politique. En Asie centrale, les Kirghizes sont en effet les seuls à posséder une épopée qui leur soit propre. Ils ont fait de l'épopée de Manas le symbole même de leur république nouvellement indépendante (au sein de laquelle les Kirghizes ne constituent qu'un peu plus de la moitié de la population), au point de fêter, en 1995, les mille ans d'une œuvre qui date, selon toute vraisemblance, des alentours du XviI ${ }^{e}$ siècle ${ }^{3}$. Ceci ne remet, bien sûr, pas en cause l'authenticité de cette épopée qui a, de plus, la particularité d'être la seule épopée d'Asie centrale ${ }^{4}$ chantée $a$ cappella. 
Ecolières jouant de la guimbarde temir ooz komuz. Kara Kuldza, Kirghiztan

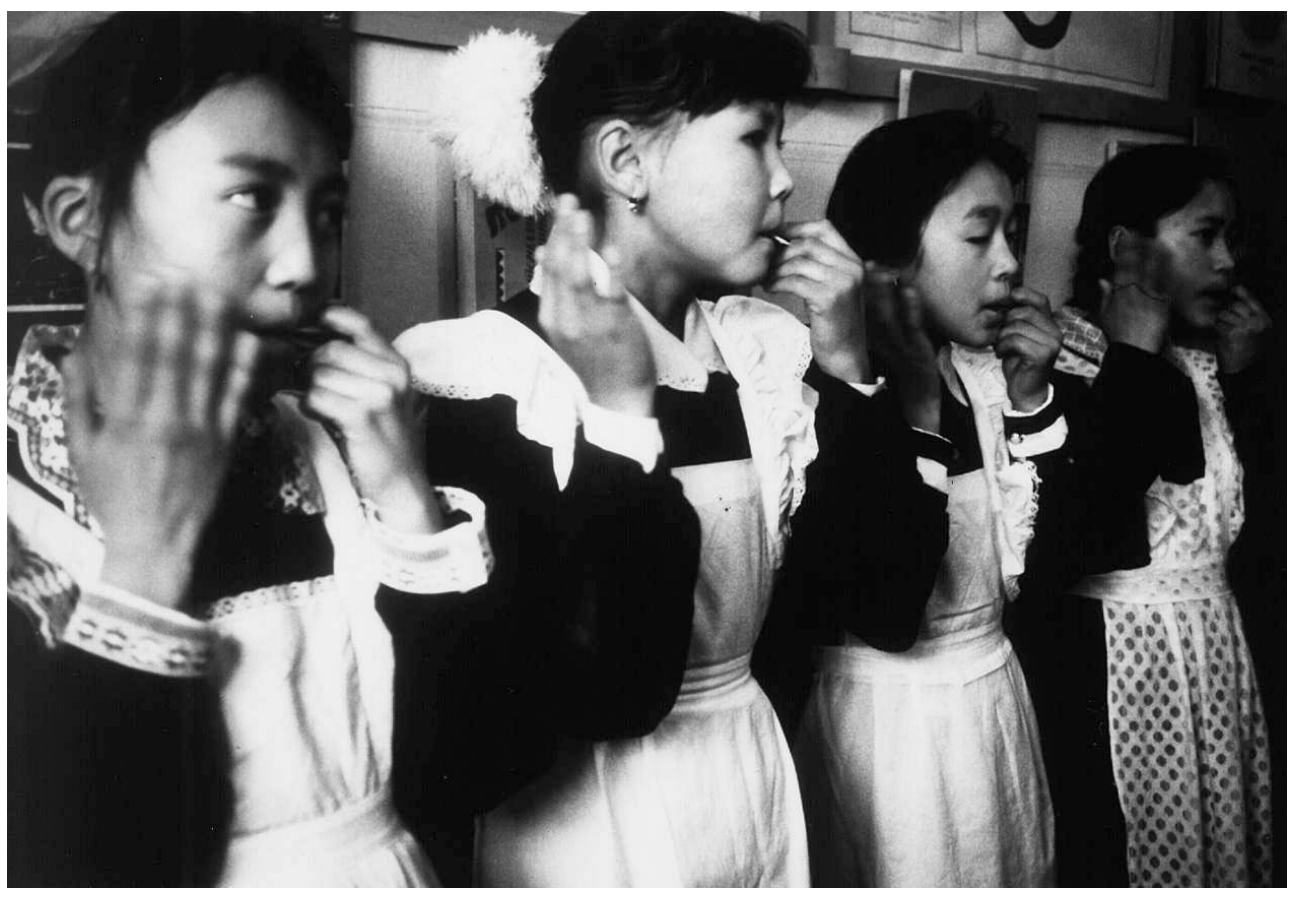

Photo: Henri Lecompte

7 Cette importance de la musique, en tant que facteur d'identité nationale, se retrouve aujourd'hui dans bien des régions de l'ex-Urss. Une des premières manifestations internationales organisées par la jeune république du Tadjikistan (en 1990), avant la terrible guerre civile qui l'a ensanglantée, a été consacrée au 1400e anniversaire de Bârbad, inventeur présumé du système de classification des modes (khosrawani), commun à la musique persane et à ses ramifications tadjike et ouzbèke. On peut d'ailleurs noter à ce sujet que seuls des musiciens tadjiks étaient présentés au cours de ce festival, avec les notables exceptions de Mohamed Reza Shadjarian pour l'Iran et de Monâjât Yultchieva pour l'Ouzbékistan.

Dans la république sakha (Yakoutie), république autonome de la fédération de Russie, la fête de l'ysyakh (où la musique est omniprésente : ronde chantée osuokhaï, chant d'éloge tojuk, guimbarde khomus, épopée olonkho) est devenue le symbole même de l'authenticité de la culture sakha, avec un retour en force du chamanisme, quasiment considéré comme la religion nationale - et, curieusement, un renouveau parallèle de l'orthodoxie. Comme chez les Kirghizes, le goût général se portera plutôt vers des acteurs-chanteurs, considérés comme parfaitement représentatifs de la culture sakha (Alexeev, 1991, Kolesov, s. d.), et qui chantent l'épopée à partir de vulgates établies par des écrivains comme Oiunskij, Fedorov ou Ksenofontov, que vers des chanteurs traditionnels qui ont appris l'épopée par transmission orale et sont devenus de plus en plus rares, tels Semion Grigorievič Alexeev-Ustrabys, dont des extraits de la version de l'olonkho n'ont jamais été publiés ailleurs qu'en Occident (Lecomte, 1993b).

9 Les événements politiques ont une grande influence sur cette notion d'authenticité. On peut se retrouver confronté, toujours dans l'ex-URSS, à un musicien ayant une démarche inverse qui consiste à cacher son authenticité. Lors de l'enregistrement d'un kamlanye (séance chamanique) mené par Delsumjaku Demneievič Kosterkin assisté de son oncle 
Boris Djukhodovič (Lecomte, 1993a), membres de l'ethnie nganasan (peuple le plus septentrional d'Eurasie), Delsjumjaku avait bien pris soin de déclarer qu'il n'était pas vraiment chamane, qu'il ne pouvait pas voler dans les trois mondes, que personne dans sa communauté n'avait recours à lui, et enfin qu'il était un «acteur». Plusieurs éléments convergents donnent cependant à penser que ces propos servaient, en fait, à le protéger ${ }^{5}$.

On pouvait déjà remarquer que les membres de cette communauté, que Delsjumjaku décrivait comme indifférente à ses activités chamaniques, lui avaient donné tous les éléments qu'ils possédaient par héritage pour reconstituer un costume indispensable au déroulement d'un kamlanye (à sa sortie de prison, séjour lié à ses activités chamaniques, son autre oncle, Tubjaku, considéré officiellement comme le dernier grand chamane nganasan, avait "offert", plus ou moins volontairement, son costume au musée de Doudinka, petite ville de la presqu'île de Taïmyr.). Autre argument, il avait effectué une partie de la séance en se poignardant symboliquement pour " écarter le suicide des jeunes ». Il semble difficile d'admettre qu'un père dont la fille s'est suicidée deux mois auparavant accomplisse cette cérémonie uniquement pour " amuser un étranger en quête d'exotisme » et gagner quelques roubles. Je ne lui avais d'ailleurs fait aucune demande particulière sur le thème de la cérémonie, qui devait être au départ une simple séance de divination (ce qui dépasse déjà d'ailleurs le rôle d'un simple " acteur »). Il avait en outre, dans une autre partie de la séance, déclaré avoir volé dans la toundra pour rencontrer Michka (l'Ours, dont il ne faut pas prononcer le nom) et était absolument épuisé à la fin de cette cérémonie, ce qui ne pouvait pas du tout s'expliquer par des raisons physiques, puisqu'il était resté assis presque tout le temps pendant les quelque quarante minutes qu'elle avait duré. D'autre part, un ami nganasan, à la fin d'une nuit bachique à Doudinka, nous avait confié qu'il avait bien souvent assisté à des kamlanye dans l'intimité des camps de chasse où l'on peut entendre l'hélicoptère de la milice une demi-heure avant qu'il arrive sur place. 
Fig. 2 :Delsumjaku Demneievič Kosterkin. Ust'-Avam, Fédération de Russie

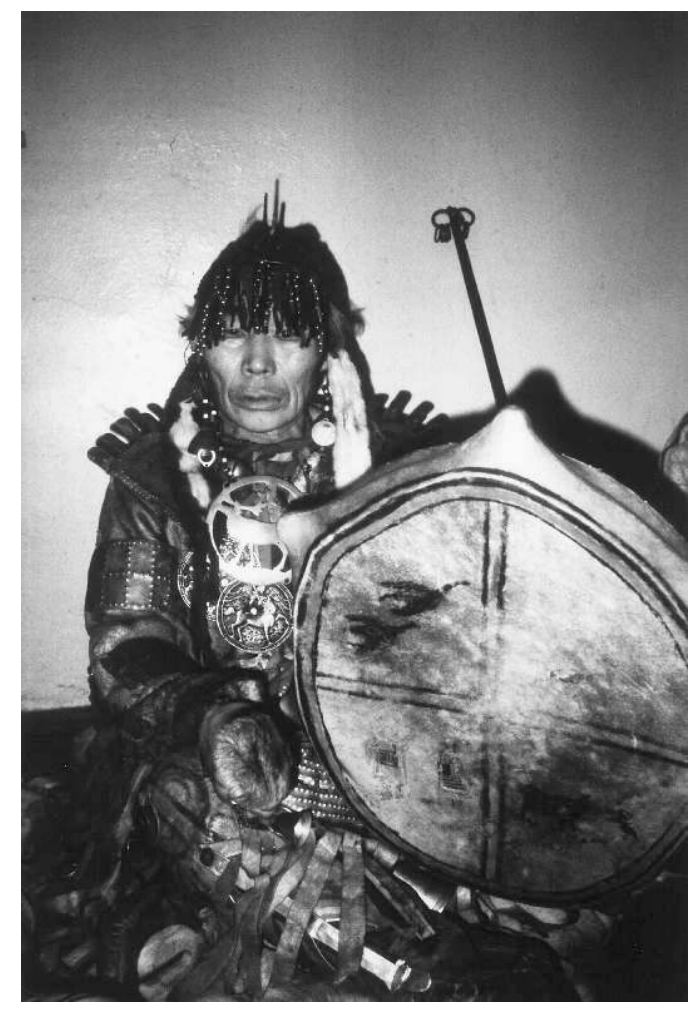

Photo : Henri Lecomte

11 Ces exemples contradictoires soulignent peut-être la difficulté de déterminer l'authenticité d'une musique, ou plutôt d'un musicien, l'authenticité considérée sous un aspect ethnique étant rarement exempte d'implications politiques.

\section{Authenticité et influences extérieures}

On sait bien que les musiques traditionnelles sont en évolution constante. Il suffit de comparer tel sitar du début du siècle, exposé à Londres, au Horniman Museum, avec un instrument comme celui que joue, par exemple, Ravi Shankar, pour se rendre compte qu'étant données les différences morphologiques entre les deux instruments, la musique a nécessairement évolué dans les mêmes proportions.

En Asie centrale, comme dans bien d'autres parties du monde, le phénomène prend cependant un autre caractère avec l'apparition de l'accordéon qui a fait depuis plusieurs décennies une entrée ravageuse, avec d'autres instruments européens, notamment depuis quelques années le synthétiseur (certains instruments non européens sont également apparus à partir du $\mathrm{XIX}^{\mathrm{e}}$ siècle, tabla et sitar indiens dans les musiques du Pamir, târ azerbaïdjanais au Tadjikistan et en Ouzbékistan).

Mes goûts personnels m'inclinent peu vers ce genre de mélanges. Il faut cependant tenir compte de la spécificité de chaque situation et surtout de l'individualité du musicien qui effectue ces choix. Ainsi, l'accordéon me semble tout à fait superflu, pour ne pas dire plus, dans la plupart des orchestres de shashmaqom que j'ai pu entendre au Tadjikistan ou en Ouzbékistan. 
Par contre, le regretté Adineh Hachemov, qui montrait déjà son originalité en interprétant aussi bien le shashmaqom que le falak, avait su parfaitement intégrer l'accordéon de son fils aîné Rahmatollah à une musique qui, précisons-le, utilise depuis longtemps des intervalles tempérés (Kasmaï et Lecomte 1991b). L'introduction de l'accordéon et une longue complicité musicale avec son fils avaient eu pour résultat qu'une prestation parisienne sans accordéon avait présenté une version bien appauvrie de la musique d'Adineh, qui m'avait d'ailleurs déclaré après le concert : «On m'a coupé les ailes...» (Lecomte 1992). Le chanteur iranien Mohamed Reza Shadjarian, qui avait assisté à plusieurs prestations d'Adineh Hashemov à Douchanbé ou au domicile d'Adineh à Moskovskiy, n'avait d'ailleurs jamais paru gêné par la présence de l'accordéon, déclarant même, lors d'une interview : "Adineh Hachemov est [...] un maître incontesté du falak, mais aussi du shashmaqom, bien qu'il ait son propre style » (Kasmaï et Lecomte 1991a). Cette allusion au style est d'ailleurs importante puisqu'elle nous amènera, dans cette recherche de ce qu'est l'authenticité, à prendre en compte le musicien en tant qu'individu, même si l'on est conscient que cette notion d'individu n'est pas la même dans toutes les sociétés.

Fig. 3 :Adineh Hachemov (târ et chant) et son fils Rahmatollah (accordéon chromatique et chant). Douchanbé, Tadjikistan

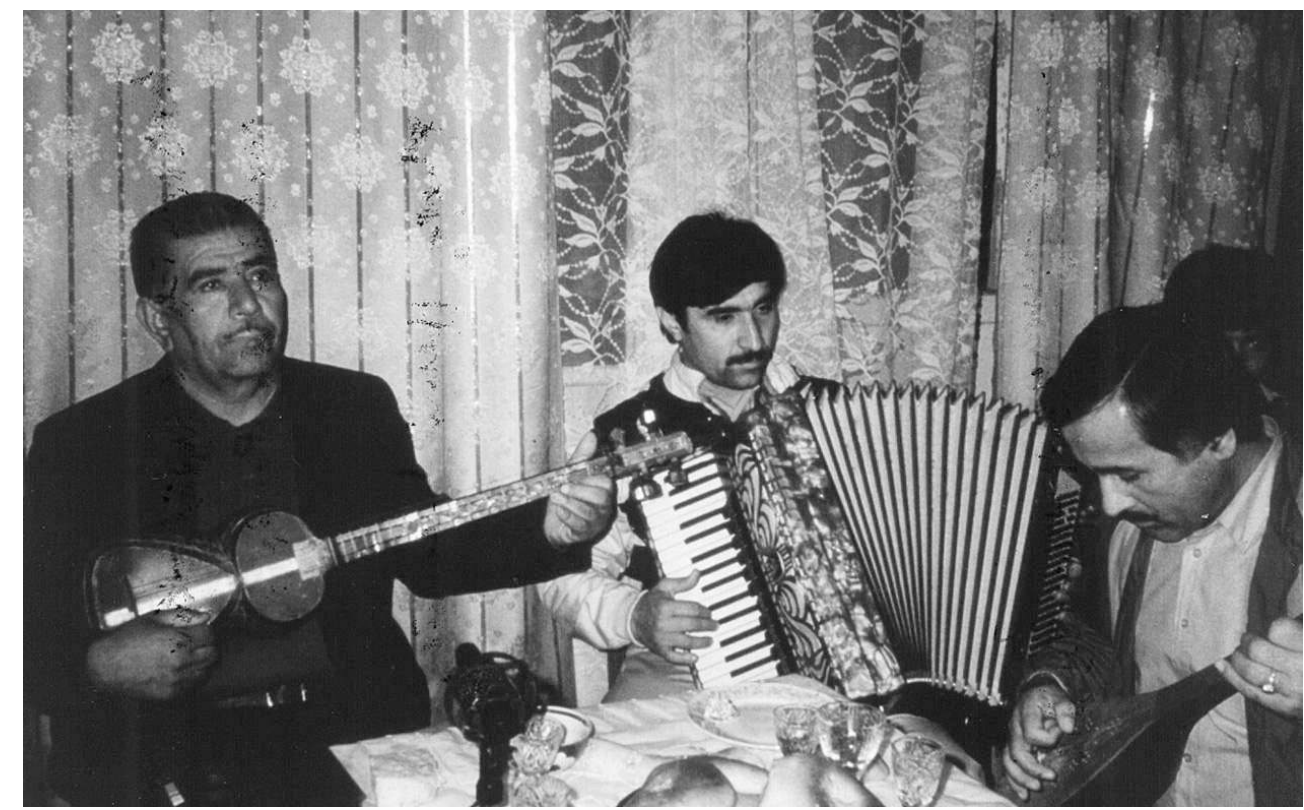

Photo : Henri Lecomte

Une remarquable chanteuse, Monâjât Yultchieva, est apparue récemment en Ouzbékistan. Elle avait séduit et étonné au festival Bârbad précédemment mentionné, en partie parce que son style paraissait révolutionnaire par rapport à celui de toutes les autres chanteuses, y compris la grande Barno Ishaqova. Alors que ses consœurs utilisaient toutes la voix de tête, Monâjât Yultchieva employait une technique qu'elle a décrite au cours d'une interview télévisée pour la chaîne franco-allemande Arte (Johnson 1994), donnant d'ailleurs en même temps une remarquable et émouvante description de ce que peut être l'authenticité, ainsi que les sources de cette «nouvelle» façon de chanter le maqom: "J'essaie de chanter avec mon cœur, pas avec ma voix, mais avec... les tourments de mon âme... L'autre manière de chanter, c'est sans le cœur. Juste pour montrer la puissance de 
sa voix. Lorsque les vieux prient "Allah Allah", ils chantent aussi avec le diaphragme, avec le ventre, comme moi. Eux aussi savent poser leur voix. Je respire, tout se gonfle et ça descend jusqu'au bassin, comme ça. Ça bouge constamment, sans arrêt. Tout simplement. C'est ainsi que je chante ».

En fait, on commence à comprendre que l'authenticité naît plus de l'émotion, du respect de l'esprit que de celui d'une lettre qui est, en fait, beaucoup plus éphémère qu'on ne le croit généralement, l'antiquité revendiquée des formes traditionnelles ne résistant souvent guère à une analyse quelque peu approfondie.

Cela ne veut pas dire, bien sûr, que toutes les initiatives, tous les apports soient souhaitables. Pour continuer à parler de mon expérience personnelle, il m'est aussi arrivé d'avoir une attitude interventionniste à l'égard d'une pratique musicale que je pensais néfaste à une certaine idée que je me faisais de l'authenticité. J'ai ainsi demandé au directeur d'un petit orchestre, en Mongolie (Billon et Lecomte 1995), de jouer sans la vièle morin khuur basse, le hautbois bishgüür (en tibétain rgya-gling)pourvu de clefs et un curieux instrument ressemblant à un cor de basset. Je pensais que, dans ce cas, l'orchestre était inutilement alourdi. Je dois dire que ma proposition a été acceptée immédiatement, sans même que le chef du groupe n'élève d'objection. Mon souci d'authenticité ne m'a cependant pas entrâné jusqu'à demander la suppression des instruments d'origine chinoise ou à exiger que l'on remplace la table d'harmonie en bois du morin khuur par la peau qui recouvre les instruments anciens!

19 Je préciserai également qu'une éventuelle crainte que les goûts occidentaux interfèrent dans l'évolution des cultures musicales n'est pas de mise dans ce type de situation. Les trois instrumentistes, mis momentanément au placard le temps d'une prise de vue, n'ont certainement pas tardé à réintégrer l'ensemble. L'influence occidentale est certainement plus néfaste lorsqu'elle amène à présenter comme musique mongole un orchestre du type symphonique incluant longues trompes tibétaines à pistons et hautbois tibétains à clefs ou bien encore un quatuor de morin khuur de tessitures différentes jouant Schubert. 
Fig. 4 : Membre d'un groupe de tsam jouant du hautbois bishgüür (tibétain rgya-gling) à clefs. OulanBator, Mongolie

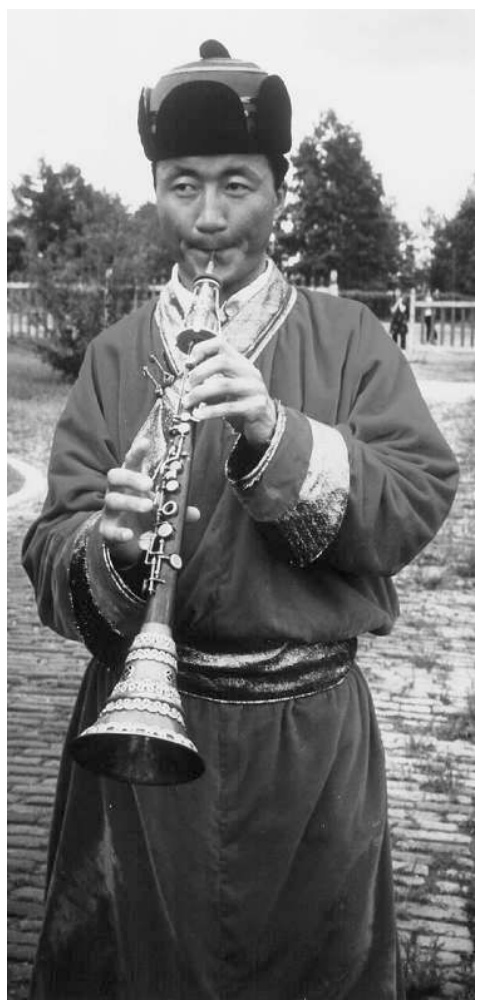

Photo : Henri Lecomte

\section{Authenticité et pratique individuelle}

L'authenticité n'est pas toujours là où on l'attend et les apparences sont parfois trompeuses. Ainsi, au Japon, il existe traditionnellement plusieurs écoles de shakuhachi. L'appartenance à l'une d'entre elles est généralement considérée comme une sorte de brevet d'authenticité. Paradoxalement, c'est l'école Tozan, la plus récemment apparue des principales écoles, et également la plus influencée par l'Occident, qui semble le plus attachée à cette notion. On peut ainsi arriver à des absurdités, comme celle d'un professeur de l'école Tozan refusant son enseignement à un élève venu de l'école Kinko, tant que celui-ci n'aurait pas changé son instrument, fabriqué par un facteur Kinko. La seule différence entre les deux flûtes est la forme angulaire du bas de l'utaguchi (pièce en corne de buffle protégeant et rendant plus précis le biseau de l'encoche) de l'école Kinko, ceux de l'école Tozan étant de forme arrondie, ce qui n'influe évidemment en aucune manière sur le son.

21 À l'opposé de cette démarche étroitement formaliste, se situe celle de Watazumi Doso, grand maître de la flûte, disparu en 1993, qui a non seulement quitté son école originelle pour fonder la sienne, mais abandonné le shakuhachi pour le dogu (ou hocchiku), énorme tube de bambou à l'intérieur duquel on a uniquement supprimé les internodes (alors que l'intérieur du shakuhachi est alésé et laqué).

On peut d'ailleurs noter que la pratique du honkyoku ${ }^{6}$, traditionnellement joué par les moines komuso, d'obédience zen,pour la méditation ou le remerciement lors de la collecte 
des aumônes, a été transmise aux laïcs. Le honkyoku est également devenu une musique de concert. Pour beaucoup de ceux qui le pratiquent, le honkyoku a cependant gardé une dimension spirituelle qui dépasse la musique, notamment pour ceux qui se réclament de l'héritage de Watazumi Doso qui écrivait: "Dans le Watazumido, le hocchiku est utilisé comme un moyen d'exprimer le doho (les principes philosophiques du Watazumido). À travers notre pratique nous essayons avant tout de donner une forme tangible au doho. Produire des sons est pour nous d'importance secondaire » (Watazumi, s. d.).

L'enseignement lui-même a radicalement changé. Yoshikazu Iwamoto m'a raconté comment il a fallu trois ans d'approches patientes à Katsuya Yokoyama pour apprendre de Watazumi Doso - et encore grâce à des informations données au compte-goutte - la pièce "San An ». Yoshikazu Iwamoto, lui, l'a apprise tout-à-fait "normalement" de Katsuya Yokoyama, par un processus d'imitation du maître que l'on retrouve dans la plupart des enseignements des arts japonais. Le même Iwamoto a eu la patience extrême de me la décortiquer minutieusement pendant toute une semaine de stage. Dans ce cas précis, indépendamment du niveau musical et de l'origine culturelle des joueurs de flûte, il est bien difficile de déterminer où s'arrête l'authenticité de la transmission. Watazumi Doso lui-même n'a sans doute pas suivi un enseignement aussi dur que celui qui était dispensé au siècle dernier et dont certaines pratiques pourraient plus évoquer un rapport sado-masochiste qu'une relation de maître à élève.

En ce qui concerne le répertoire, le passage d'un professeur à un autre permet vite de se rendre compte que la même pièce, y compris au sein de la même école, a plusieurs variantes, qui peuvent être régionales et liées à un temple komuso donné, mais aussi différer selon les interprètes. On peut dire, en fait, que chaque maître a sa propre version, laquelle peut même évoluer au cours de sa vie artistique. Il suffit de comparer les nouvelles versions de treize honkyoku des deux disques compacts de Katsuya Yokoyama, parus chez Eûros (Yokoyama 1989, 1993), avec celles qu'il avait enregistrées auparavant dans un double disque compact Wergo (Yokoyama 1976). À l'exception de la version de " Hon shirabe " qui est jouée plus rapidement, la plupart des nouvelles versions sont considérablement plus longues, par étirement des phrases parfois mais surtout parce qu'il s'agit de variantes. C'est, en fait, à chacun de trouver sa propre liberté, en s'efforçant de rester fidèle à l'esprit de l'instrument. Un jour que j'interrogeais mon maitre, Yoshikazu Iwamoto, sur l'éventuelle utilisation de coups de langue, que je pensais être pratiquement «interdits », celui-ci me répondit : «Dans la pratique du shakuhachi, tout est permis ». Il ne faut pas en conclure qu'il s'agit d'un musicien laxiste mais que, rejetant tous clichés répétés mécaniquement, son enseignement réaffirme la totale mobilité de la musique, à l'instar de chaque note émise qui est sans cesse entraînée dans un mouvement interne, évoquant l'idée d'impermanence (mujô), si présente dans la pensée influencée par le zen. Cette authenticité nécessaire au joueur de shakuhachi se manifeste aussi par le conseil de jouer à chaque fois comme s'il découvrait l'instrument et même de cultiver une certaine forme de maladresse. Cette recommandation ne doit pas être prise au pied de la lettre, mais contribue à cultiver l'authenticité en permettant à l'élève de trouver luimême ses propres solutions à partir de conseils parfois difficiles à comprendre. Même si les maîtres existent et sont indispensables, il convient de considérer avec circonspection cette notion d'écoles. Celles-ci existent indubitablement ${ }^{7}$ et l'esthétique de la Tozan-ryû est, sans nul doute, très éloignée de celle de la Kinko-ryû. La différence n'est pas moins grande entre deux musiciens issus tous les deux de la Kinko-ryû, comme Yamaguchi Gorô et Katsuya Yokoyama. 
Certains maîtres donnent en exemple l'histoire d'Ikkyû Sôjun (1394-1481), figure marquante du zen de l'école Rinzai et maître du shakuhachi qui, atteignant l'éveil (satori) après avoir entendu au matin le chant d'une corneille, déchire le certificat de confirmation de maitre spirituel qui lui est enfin accordé, après des années de méditation. On est loin des pratiques de certaines écoles actuelles promptes à décerner à qui mieux mieux les brevets de shihan (maitre). L'authenticité et la tradition passent alors par la voie étroite et périlleuse de la trangression des règles (étant entendu que l'on ne peut les transgresser que si on en a une parfaite connaissance $)^{8}$.La vie de Watazumi Doso est, à cet égard, parfaitement exemplaire.

C'est peut-être d'ailleurs là que l'on peut trouver une amorce de solution à ce problème de l'authenticité : le musicien traditionnel respecte plus le fonds musical que la lettre, à l'opposé du musicien folklorique qui ressasse sans cesse les mêmes versions. La folklorisation est d'ailleurs l'un des moyens utilisés par les gouvernements pour détruire l'identité des populations minoritaires ou colonisées, comme cela a été le cas en URSS, laquelle a toujours favorisé les expressions harmonisées des musiques des républiques asiatiques (pendant longtemps le théoricien de la «question des nationalités » était un certain Joseph Djougachvili, plus connu sous son pseudonyme de Staline). Les artistes authentiques, comme le joueur azerbaïdjanais de târ Bahram Mansurov, dont la musique était considérée comme un vestige de l'époque féodale des khanats, n'ont d'ailleurs jamais été autorisés à se produire en Europe (Daniélou 1981). Il se passe des phénomènes similaires en Chine, où les autorités tentent d'imposer un modèle unique et figé des douze muqam aux musiciens ouigours (Trébinjac 1990).

\section{Authenticité, « terrain », scène occidentale}

Une des questions récurrentes liées aux rapports entre les musiques traditionnelles et l'Occident est la présentation sur scène de ces expressions musicales. Je ne parlerai pas de la scénographie proprement dite, n'ayant aucune expérience en la matière autre que celle de spectateur.

En ce qui concerne les musiques elles-même, le problème ne se pose guère quand il s'agit de musiques comme le flamenco, le râga sangîta indien, ou des solistes de komuz kirghizes, membres d'un ensemble d'état comme Kambarkan. Bien sûr, on pourra rétorquer que le public européen ne réagira pas de la même manière qu'un public local, même si les salles de concert, en Inde, en Espagne ou au Kirghizstan, ne sont guère différentes de leurs homologues françaises, américaines ou suisses. Le problème vient plutôt de l'auditeur luimême que de l'endroit géographique où se déroule le concert. A moins de nous être totalement immergé dans une culture, comme ont su le faire certains musiciens occidentaux, nous n'aurons jamais la même perception de la musique que celui qui a été élevé dans la culture dont cette musique est originaire.

La question devient quelque peu différente lorsque l'on est confronté à des musiques qui ne sont pas des musiques "d'art», mais ont un caractère intime ou rituel. L'enregistrement ne rend pas compte non plus de l'ensemble des éléments qui font le caractère unique et authentique de ces musiques. Il est certain que l'on n'a pas la même perception de la musique korjak, quand on l'entend dans un village après avoir passé six heures sur un traîneau dans la toundra hivernale (surtout quand on connaît le rapport intime entre les musiques de Sibérie et la nature) qu'en assistant à un concert des mêmes 
chanteuses sur la scène parisienne de la Maison des Cultures du Monde (concerts que je ne cherche d'ailleurs pas à dénigrer et qui n'ont pas été pour rien dans mon désir d'aller sur place enregistrer ces musiques). Remarquons aussi à ce sujet qu'en ce qui concerne l'ex-URSS, la plupart des musiciens traditionnels font ou ont fait partie de groupes folkloriques, mais ces groupes folkloriques ne constituent pas une entité homogène. La notion de folk'lor en ex-URSS est bien différente de son acception en Europe de l'Ouest, puisque tout y passe, depuis les grands solistes de mugam jusqu'aux troupes présentant des expressions très stylisées, comme le ballet Mengo des Korjak, en passant par des expressions fortement enracinées comme les chants de gorge Čukč. Ces groupes peuvent avoir un statut international et ont longtemps servi de vitrine pour montrer à quel point le socialisme scientifique prenait en considération les cultures nationales, en les guidant sur la voie triomphale de l'harmonie et de la gamme tempérée. Mais il y a aussi beaucoup de groupes purement locaux qui se produisent uniquement dans le klub du village (qui est souvent un des endroits où se conserve l'usage de la langue vernaculaire, dans le cas notamment des ethnies sibériennes qui ne comptent parfois que quelques centaines de locuteurs), équivalent des Maisons de la culture mises en place en France par André Malraux. Les membres de ces groupes pratiquent souvent des musiques sans aucune influence européenne, alors même que les jeunes gens et les jeunes filles qui en font partie ont des rapports quotidiens avec la musique occidentale. À Tymlat, petit village du Kamtchatka peuplé de Korjak irréductibles dont la réputation évoque celle du village gaulois d'Astérix, j'eus la surprise de retrouver une jeune femme que j'avais rencontrée au klub dans l'après-midi, vêtue d'une robe fluo et dansant sur de la musique techno, interpréter, le soir, un admirable chant traditionnel (avec un engagement physique impressionnant, yeux clos et visage couvert de sueur au bout de quelques secondes) en s'accompagnant du tambour jajar (Lecomte 1994, plage 23). Précisons que traditionnel ne signifie pas ici chant ancien, repris de quelqu'un d'autre, mais chant personnel qu'elle avait composé, comme c'est justement la tradition dans plusieurs cultures sibériennes.

Dans la région de la Kolyma, dans le Grand Nord de la république sakha, le chanteur Čukč Slava Egorovič Kemlil (Lecomte 1993c) utilise les mêmes techniques vocales et a pratiquement le même répertoire, qu'il s'accompagne lui-même sur son tambour jarakh ou qu'il se produise avec son groupe de rock, qui comprend batterie, basse électrique et claviers électroniques.

Dans un groupe folklorique, venu du Tadjikistan pour se produire notamment à la Maison des Cultures du Monde, se trouvaient des musiciens comme Goltchereh Sadikhova ou le chanteur d'épopée Pîr Nazar Hagh-Nazarov, qui ont dans leur pays des pratiques tout à fait traditionnelles. Goltchereh Sadikhova consacrait notamment l'essentiel de ses activités professionnelles à des mariages ou d'autres fêtes locales, dans la petite ville de Koulab et ses environs, ce qui ne l'a pas empêchée de me demander de l'accompagner à Pigalle acheter pour son fils un synthétiseur, symbole de professionnalisme et susceptible de rapporter de nombreuses « affaires »!

L'influence occidentale qui paraît inévitable, (la chaîne de télévision MTV, diffusée par satellite, inonde maintenant de ses programmes de rock music la majeure partie de l'Eurasie) n'est pas forcément destructrice de toutes les particularités. Ainsi, le chanteur tadjik Davlatmand, passé par le conservatoire, en a gardé une approche sans doute européanisée de la technique vocale, mais est aussi un des rares musiciens que j'ai entendu au Tadjikistan jouer sur son ghidjak des intervalles non tempérés. En tout cas, 
l'idéal ne me semble pas de créer des réserves culturelles. Nous n'en avons d'ailleurs heureusement pas la possibilité.

Dans l'un et l'autre cas (Kamtchatka et Tadjikistan), je n'ai pas ressenti ces musiques de la même manière sur place et à Paris. Que les musiciens aient été authentiques dans un cas et dans l'autre non me paraît par contre très discutable. Il y a parfois à ce sujet une certaine confusion, due au fait que l'on met volontiers en cause l'authenticité de l'interprète, mais que l'on se soucie plus rarement de se poser des questions sur l'auditeur.

En ce qui concerne les musiques collectives, la notion d'authenticité est également perçue de manière différente. L'observateur étranger qui assiste à une fête de l'ysyakh, en Yakoutie, peut avoir la tentation d'établir des catégories, en discernant les musiques traditionnelles « authentiques » comme la ronde osuokhaï et le chant d'éloges tojuk, et les musiques « acculturées » comme les chanteuses chantant en sakha accompagnées par un accordéoniste ou des chœurs harmonisés. Mais on retrouvera, à un autre moment de la fête, l'accordéoniste mener le chant à répons de l'osuokhaï. Ce qui paraît authentique de manière indiscutable aux participants, c'est l'ensemble de la fête : musique, lutte, course de chevaux, acteurs déguisés en chamanes blancs recréant des cérémonies anciennes connues par les récits des déportés polonais au début du XIX ${ }^{e}$ siècle, le tout est perçu de façon globale.

L'authenticité doit être appréhendée à trois niveaux : l'aspect ethnique se mêle à l'aspect politique, même si le nombre des Sakha par rapport aux Européens à l'intérieur de leur propre république rend peu crédible toute velléité d'indépendance. Une fois de plus, la musique est mise à contribution pour forger une identité nationale. L'enseignement des instruments et des formes vocales sakha est très répandu dans les écoles et la volonté politique est évidente dans ces expressions musicales.

A côté de cette "authenticité d'état", transmission de la tradition et innovations individuelles ont toujours marché de pair. Les modèles d'authenticité me paraissent être des musiciens qui ont su être novateurs, tout en gardant l'esprit profond de leur culture, comme Monâjât Yultchieva ou Watazumi Doso.

37 Ces exemples prouvent peut-être qu'il n'y a pas de notion universelle d'authenticité. C'est sans doute aussi le cas pour le concept de musique «traditionnelle », mais comme aurait pu le dire l'auteur de « Kim » : « ceci est une autre histoire».

\section{BIBLIOGRAPHIE}

ALEXEEV Ivan, 1991, Ivan Alexeev. Olonkho khatan erbiie bukhatyyr. itaet Afanasiy Fedorov. Coffret de trois disques microsillonsMelodija C 4031225003.

BILLON Yves et LECOMTE Henri, 1995, Musiques de Mongolie. Documentaire vidéo. Les Films du Village, Buda Records 92641-8. Durée : 52'.

DANIÉLOU Alain, 1981, Le chemin du labyrinthe. Souvenirs d'Orient et d'Occident. Paris : Robert Laffont. 
FEDOROV G., s. d., Niourgoun Bootur Stremitelnyi. Olonkho. P. A. Oiunskij. Coffret de neuf disques microsillons. Melodija D 024539, 541, 543, 545, 595, 597, 600, 601, 603.

IWAMOTO Yoshikazu, 1994, The Potential of the Shakuhachiin Contemporary Music, Contemporary Music Review, vol. 8, Part 2, Harwood Academy Publishers.

JOHNSON Thomas, 1994, Reportage : Monâjât (Ouzbékistan). Documentaire vidéo. Megamix 173.

KASMAI Sorour et LECOMTE Henri, 1991a, « Le pèlerinage aux sources. Mohamed Reza Shadjarian au Tadjikistan », Cahiers de musiques traditionnelles 4 [Dossier : « Voix »] : 247-253.

KASMAI Sorour et LECOMTE Henri, 1991b, Tadjikistan. Musiques populaires du sud. Disque compact Fonti Musicali fmd 189.

LECOMTE Henri, 1992, «L'avant-dernière tentation de l'Occident ». Trad Magazine $\mathrm{N}^{\circ}$ 20, janvierfévrier.

LECOMTE Henri, 1993a, Sibérie 1. Nganasan. Chants chamaniques et narratifs de l'arctique sibérien. Disque compact Buda Records, collection Musique du Monde, 92564-2.

LECOMTE Henri, 1993b, Sibérie 2. Sakha. Yakoutie : Épopées et improvisations. Disque compact Buda Records, collection Musique du Monde, 92565-2.

LECOMTE Henri, 1993c, Sibérie 3. Čukč. Even. Jukaghir. Kolyma: Chants de nature et d'animaux. Disque compact Buda Records, collection Musique du Monde, 92566-2.

LECOMTE Henri, 1994, Sibérie 4. Korjak. Kamtchatka : Tambours de danse de l'extrême-orient sibérien. Disque compact Buda Records, collection Musique du Monde, 92598-2.

LECOMTE Henri, 1995, Musiques du Kirghizstan. Disque compact Buda Records, collection Musique du Monde, 92631-2.

MABRU Lothaire, 1988, Musique, musiques... Pratiques musicales en milieu rural (XIXe-XXe siècle). L'exemple des Landes de Gascogne. Floirac : Centre Lapios.

TRÉBINJAC Sabine, 1990, « Musique ouigoure de Chine : de l'authenticité à la folklorisation », in Rémy Dor (éd), L'Asie centrale et ses voisins. Influences réciproques. Paris: INALCO.

WATAZUMI DOSO, s. d., Watazumido. The book of Meditation. The Difference between Watazumido and Music. Polycopié.

YOKOYAMA Katsuya, 1982, Zen. Katsuya Yokoyama plays classical shakuhachi masterworks. Coffret de deux disques compacts Wergo SM 1033/34-50.

YOKOYAMA Katsuya, 1989, Katsuya Yokoyama plays shakuhachi, vol. 1. Disque compact Eûros OCD-0911.

YOKOYAMA Katsuya, 1993, Katsuya Yokoyama plays shakuhachi, vol. 2. Disque compact Eûros OCD-0912.

\section{NOTES}

1. Remarquons que, en ce qui concerne le luth, les conservatoires utilisent la notation occidentale.

2. La notion d'authenticité est bien souvent liée à celle d'ancienneté. Dans la musique sacrée occidentale, ce que l'on a appelé plus tard modes authentiques (ou authentes) sont des modes de l'antiquité grecque (dorien, phrygien, lydien, mixolydien), conservés par Saint Ambroise, évêque de Milan (340-397), auxquels s'ajouteront, deux cents ans plus tard, les quatre modes plagaux. 
3. Assez curieusement, cette volonté de rattachement au passé de sa propre culture se retrouve aussi dans des domaines très divers, en apparence très éloignés de celui des musiques traditionnelles (musique classique européenne, avec des œuvres comme «Le tombeau de Couperin », de Maurice Ravel, mouvement « roots " dans le reggae, œuvres africaines urbaines comme « Regard sur le passé » de l'orchestre guinéen Bembeya Jazz National, grands créateurs afro-américains : John Coltrane rendant hommage à Sidney Bechet, Thelonious Monk à Duke Ellington, Charles Mingus à l'église baptiste, Billie Holiday à Bessie Smith, Sun Ra à Fletcher Henderson, Archie Shepp à Ben Webster... La liste pourrait continuer longtemps.).

4. Les limites de l'Asie centrale varient selon les auteurs. Nous l'employons ici pour désigner les cinq républiques asiatiques de l'ex-URSS (Kazakhstan, Kirghizstan, Ouzbékistan, Tadjikistan et Turkménistan), ainsi que la région chinoise du Xinjiang.

5. Même si les Nganasan ont été relativement épargnés, la répression du chamanisme par les soviétiques a été épouvantable

6. Musique de méditation, jouée le plus souvent en solo, et non mesurée.

7. Il existe, par exemple, une généalogie des maîtres de l'école Kinko qui remonte au XVIII ${ }^{\mathrm{e}}$ siècle, avec Kurosawa Kôhachi, premier à prendre le nom de Kinko. Les trente-trois honkyoku qu'il avait sélectionnés, ajoutés aux trois pièces anciennes (koden sankyoku) collectées ou composées à la fin du XIII ${ }^{e}$ siècle par Kakushin, disciple du maître du ch'an du IX ${ }^{\mathrm{e}}$ siècle Fuké (en chinois P'u-huan), constituèrent le répertoire des trente-six pièces de base de la Kinko-ryû. Il est cependant permis de douter que ces morceaux se jouent maintenant comme il y a sept siècles, les versions de chaque œuvre étant nombreuses et la notation actuelle, qui ne donne que la ligne mélodique générale, datant de la fin du XIX ${ }^{\mathrm{e}}$ siècle.

8. Yoshikazu Iwamoto a introduit de nouvelles techniques qu'il utilise dans sa pratique de la musique contemporaine. Il écrit d'ailleurs à ce propos (Iwamoto 1994) : «Un des points de vue que j'ai acquis en travaillant cette musique est que dans le shakuhachi se cache plus de diversité que quiconque ne l'avait jamais imaginé. Le potentiel du shakuhachi a été augmenté en jouant de la musique contemporaine, en ce sens qu'en la pratiquant on accède à une vision plus profonde de la musique de shakuhachi passée ou présente».

\section{RÉSUMÉS}

C'est à partir d'exemples observés en Sibérie et en Asie centrale ou liés à la pratique de la flûte shakuhachi, que l'auteur développe certaines questions sur le thème de l'authenticité. Le terme doit être entendu ici dans un sens anthropologique lié à l'adéquation d'une expression musicale avec la culture dont le musicien est issu.

On peut d'abord constater que la musique est souvent considérée comme un symbole de l'authenticité nationale. L'authenticité peut être aussi cachée, lorsque des musiques liées à des pratiques spirituelles ont été interdites par le pouvoir politique.

L'authenticité peut aussi être liée à l'idée d'antiquité. Ainsi se créent des écoles, dont on ne peut nier l'importance. On constate cependant que l'individu y a un pouvoir de création plus grand qu'on ne l'imagine généralement. Un respect trop grand de certaines formes du passé risque d'entraîner la folklorisation, moyen utilisé par les gouvernements centraux pour déculturer les peuples colonisés ou minoritaires.

Outre la perception différente que peuvent en avoir l'observateur étranger à une culture et les 
membres de celle-ci, l'authenticité doit être appréhendée à trois niveaux : politique (national), ethnique et individuel.

Au niveau individuel, on la trouvera plutôt chez des musiciens qui ont su être novateurs tout en gardant l'esprit profond de leur culture, comme la chanteuse ouzbèke Monâjât Yultchieva ou le joueur de flûte japonais Watazumi Doso, que dans le respect sclérosé des formes du passé.

Based on examples observed in Central Asia and Siberia or linked to the practice of the shakuhachi flute, the author considers a number of questions related to the topic of authenticity. The term authenticity should be understood here in an anthropological sense as the perfect adaptation of musical expression to the culture from which the musician hails.

One may first of all note that music is often considered as a symbol of national authenticity. What is genuine and 'authentic' may also be hidden away, as when for instance, music linked to spiritual worship is banned by political authorities. Authenticity may also be linked to the idea of ancientness. Thus schools have been created the importance of which is undeniable. One may note however, that the individual possesses greater creative powers than is often imagined. Undue respect for the past may bring about undue glorification of folklore, often a way by which some central governments 'deculture' minorities and people they have colonized.

Apart from the different perception that an outsider may have of a culture and its members, the question of authenticity should be assessed from three standpoints: political (national), ethnic and individual. At an individual level one finds 'authenticity' much more in innovative musicians who have been able to preserve the profound spirit of their culture such as the Uzbek singer Monajat Yultcheva or the Japanese flautist Watazumi Doso, than in a hidebound representation of the past.

\section{AUTEUR}

\section{HENRI LECOMTE}

Henri LECOMTE a (ou a eu) des activités diverses dans le domaine des musiques traditionnelles (animations scolaires, radio, presse écrite, télévision, édition de disques compacts). 